\title{
PAPAN INFORMASI DIGITAL BERBASIS RASPBERRY PI MENGGUNAKAN JARINGAN WIRELESS DISTRIBUTION SYSTEM
}

\author{
Rohmat Tulloh \\ Fakultas Ilmu Terapan, Program Studi D3 Teknik Telekomunikasi \\ Universitas Telkom \\ Email: rohmatth@telkomuniversity.ac.id \\ Yuli Sun Hariyani \\ Fakultas Ilmu Terapan, Program Studi D3 Teknik Telekomunikasi \\ Universitas Telkom \\ Email: yulisun@tass.telkomuniversity.ac.id \\ Mochammad Fakhrizal Hafidh \\ Fakultas Ilmu Terapan, Program Studi D3 Teknik Telekomunikasi \\ Universitas Telkom \\ Email: fakhrizal.hafidh@gmail.com \\ Ayu Warni Pertiwi \\ Fakultas Ilmu Terapan, Program Studi D3 Teknik Telekomunikasi \\ Universitas Telkom \\ Email: ayuwarnip@gmail.com
}

\begin{abstract}
ABSTRAK
Papan informasi digital adalah media digital untuk menampilkan informasi dalam bentuk visual yang dapat dinikmati oleh orang-orang disekitarnya. Media digital bisa menjadi sarana informasi, promosi produk, dan juga sebagai sarana berita terbaru. Papan informasi digital biasanya menggunakan layar LED TV dilengkapi 1 unit komputer dan menggunakan kabel sebagai media transmisi. Banyaknya jumlah TV dan komputer yang digunakan menimbulkan masalah biaya dan tempat, disamping itu manajemen konten informasi yang ditampilkan menjadi tidak praktis karena dilakukan langsung satu persatu di setiap CPU. Penelitian ini membuat solusi sistem informasi terpadu berbasis web yang ditanam pada mini komputer berupa raspberry pi menggunakan jaringan wireless distribution system (WDS). Perangkat digital berupa LED TV dilengkapi dengan raspberry pi sebagai interface dan ternyata terbukti menghemat daya, biaya serta tempat. Kemudian pada penelitian ini juga ditambahkan manajemen konten informasi yang terintegrasi dengan komputer server yang menyediakan layanan edit fitur, update informasi, video streaming dan live streaming. Solusi yang telah kami buat ternyata memenuhi semua persyaratan Quality of Service (QOS) standar Telecommunications and Internet Protocol Harmonization Over Networks (TIPHON) pada saat skenario kondisi Line of Sight (LOS) maupun Non Line of Sight (NLOS). Selain itu didapatkan cakupan WDS dari server ke raspberry pi client mencapai 70 meter dengan kondisi LOS maupun NLOS. Pengujian Mean Opinion Score (MOS) didapatkan nilai rata-rata sebesar 4 atau dalam kategori puas dengan sistem yang dibuat.
\end{abstract}

Kata kunci: papan informasi, raspberry pi, WDS, video streaming,

\begin{abstract}
Digital information boards are digital media for displaying information in a visual form that can be enjoyed by the people around them. Digital media can be a media of information, product promotion, and also as a media of the latest news. Usually digital information boards use LED TV with 1 computer unit and using cable as a transmission media. The large number of TVs and computers used cause cost and place problems, besides the content management information that is displayed to be ineffective because it is done directly on each CPU one by one. This research makes integrated web-based information system solution which is inserted on a mini computer in the form of raspberry pi using wireless distribution system (WDS) network. A Digital device in the form of LED TV installed raspberry pi as interface and proven to save power, cost, and place. Later in this study also added information content management integrated with server computers that provide feature editing services, information update, streaming video and live streaming. The solutions we have developed comply with all Telecommunications and Internet Protocol Harmonization Over Networks (TIPHON) standard of Telecommunications and
\end{abstract}


Internet Protocol Harmonization Over Networks (TIPHON) requirements during the Line of Sight (LOS) and Non-Line of Sight (NLOS) scenarios. In addition, WDS coverage from the server to raspberry pi client reached 70 meters with LOS or NLOS conditions. Testing Mean Opinion Score (MOS) obtained an average value of 4 or in the category satisfied with the system created.

Keywords: information boards, raspberry pi, WDS, video streaming.

\section{PENDAHULUAN}

Papan informasi digunakan di institusi, organisasi atau tempat utilitas umum seperti kampus perguruan tinggi, stasiun kereta api, namun mengirimkan berbagai pemberitahuan dari hari ke hari adalah proses yang berat[1]. Papan informasi digital dapat berfungsi sebagai media center pada pameran dan dapat menjadi solusi yang tepat dari permasalahan tersebut, dapat menghemat anggaran tanpa harus membeli flashdisk dan DVD[2]. Dalam beberapa tahun terakhir, proliferasi teknologi seperti IEEE 802.11, 3G dan bluetooth telah mengarahkan banyak perhatian pada berbagi informasi nirkabel. Saat ini berbagi informasi melalui gelombang radio dan bluetooth telah mendapat momentum. Tapi teknologi ini memiliki keterbatasan seperti, perangkat tujuan untuk sistem berbagi tidak bisa berjalan terlalu jauh dari sumber dan jangkauannya tidak bisa melebihi 10 meter[3].

Perkembangan papan informasi digital cukup beragam, hal ini terlihat dari banyaknya penelitian yang memberikan solusi dan pilihan sesuai kebutuhan. Beberapa penelitian terbaru menjadi latarbelakang penelitan yang kami lakukan. Pada paper K. Siddharthraju dan D. Dhivya[3] melakukan perancangan dan implementasi Wireless Interaktif Display menggunakan Raspberry pi yang berfokus pada lingkungan perguruan tinggi namun dapat dirancang untuk kebutuhan industri. Sistem distribusi informasi yang diusulkan menerima informasi dan mentransmisikannya melalui USB WIFI dongle ke papan tampilan TFT oleh web hosting. Raspberry pi mengoperasikan dan mengendalikan layar TFT untuk interaksi dan pemutaran berita langsung. Kemudian penelitian oleh A. Jyoti S, B. Vedika, dkk [1] membuat sistem yang memungkinkan orang mengirim pemberitahuan nirkabel di papan pengumuman menggunakan bluetooth dengan smart phone dan pengguna mendapatkan pemberitahuan otomatis menggunakan parse cloud. Pengoperasiannya didasarkan pada mikrokontroler ATMEGA 328P yang diprogram dalam bahasa C. Lalu pada penelitian lainnya yang dilakukan oleh R. Panuntun, A.F. Rochim dan K.T. Martono [4], mengimplementasikan komputer mini raspberry-pi sebagai perangkat digital signage yang menghasilkan papan informasi digital berbasis web yang hemat energi dan efisien. Solusi lainnya juga dikemukakan oleh V.B. Jadhav dkk [5] yang mengajukan pemberitahuan dari jarak jauh kepada digital monitor dari aplikasi android berdasarkan kartu Raspberry pi. Wi-Fi digunakan untuk transmisi Data. Dari penelitian diatas belum ada yang mengembangkannya menggunakan teknologi wireless distribution system (WDS).

WDS adalah sistem tanpa kabel yang menggabungkan dua atau lebih Access Point dengan suatu Wireless Local Area Network (WLAN)[6]. Dengan teknik WDS ini Access Point berkomunikasi secara wireless, sehingga instalasi menjadi lebih mudah dengan biaya yang lebih murah. Mode pada WDS bisa di bagi dua macam yaitu mode bridge dan mode repeater [7]. Teknologi WDS menggunakan Media Access Control (MAC) untuk membangun hubungan dengan kelompok WDS, Hal Ini artinya membangun konektivitas ke lapisan data link model OSI [8]. Dengan WDS ini, area kerja dari WLAN dapat diperluas tanpa menggunakan router dengan sistem backbone kabel. Dengan kata lain, WDS adalah metode untuk menghubungkan beberapa access point atau router dalam suatu WLAN tanpa mengubungkan beberapa akses poin atau router tersebut dengan kabel.

Untuk membangun WDS, dibutuhkan setidaknya dua atau lebih access point. Untuk melakukan distribusi akses nirkabel, beberapa access point tersebut dikonfigurasikan dengan parameter Service Set Identifier (SSID) dan frekuensi yang sama serta masing-masing access point mendaftarkan MAC Address dari tiap akses poin yang akan terhubung dengan jaringan. Dengan demikian maka beberapa access point tersebut akan terlihat sebagai satu kesatuan jaringan. Penerapan pada jaringan yang akan digunakan unuk mengakses internet, umumnya dilakukan dengan menggunakan minimal satu acess point yang terhubung dengan sistem kabel yang disebut root AP. Root AP inilah akses nirkabel akan didistribusikan ke beberapa akses poin yang akan menjadi repeater AP. Teknologi yang diciptakan selalu ada kelebihan dan kekurangannya termasuk WDS yang memiliki kelebihan walaupun packet traffic dilewatkan melalui link access point yang berbeda namun header MAC address-nya tidak akan berubah. Sedangkan kekurangan WDS yaitu tidak bisa menggunakan kunci enkripsi dinamis sehingga hanya mendukung penggunaan kunci statik seperti WEP atau WPA, selain itu ada kekurangan lainnya yaitu keterbatasan throughput yang akan terbagi dua setelah hop dibuat.

Raspberry pi adalah papan komputer tunggal (Single Board Circuit) yang memeliki ukuran sebesar kartu pelajar. Raspberry pi dapat digunakan sebagai media center karena hardware yang dimiliki Raspberry pi dapat memutar video HD[2]. Sistem operasi yang digunakan Raspberry pi adalah Debian GNU/Linux dan bahasa pemograman Python[9]. Video streaming merupakan teknologi untuk menonton 
video secara langsung tanpa adanya proses penyimpanan video/audio ke dalam hardisk lokal client ataupun dengan pre-recorded dari server. File video yang tersimpan pada server, secara langsung dapat dimainkan oleh client setelah client mengirimkan permintaan (video on demand) tanpa melalui proses mengunduh.

Dalam penelitian ini parameter yang diperhatikan salah satunya adalah delay. Delay dapat dipengaruhi oleh waktu propagasi, waktu transmisi, waktu tunggu dan waktu proses di setiap titik. Parameter lainnya adalah Jitter atau variasi delay merupakan perbandingan dua buah paket yang ditransmisikan secara berurutan. Dimana variasi delay ini diperoleh dari delay paket yang ditransmisikan terakhir dikurangi delay dari paket pertama. Sedangkan parameter throughput juga diamati karena menunjukkan jumlah data/bit yang sukses diterima dengan benar berdasarkan waktu pengamatan dengan satuan bit per second (bps).

\section{METODE PENELITIAN}

Langkah-langkah pada penelitian ini adalah: (1) Merancang topologi jaringan WDS (2) Merancang web Interface, (3) Konfigurasi server dan menanamkan web interface ke raspberry pi, (4) Pengujian fungsionalitas dan pengukuran QOS, (5) Analisa hasil dan kesimpulan.

\subsection{Merancang Topologi Jaringan WDS}

Topologi WDS yang digunakan untuk penelitian ini adalah mode bridge seperti pada gambar 1 yaitu menggunakan dua buah access point yang terhubung secara point to point dimana access point menjadi extend atau perpanjangan coverage dari AP yang lain.

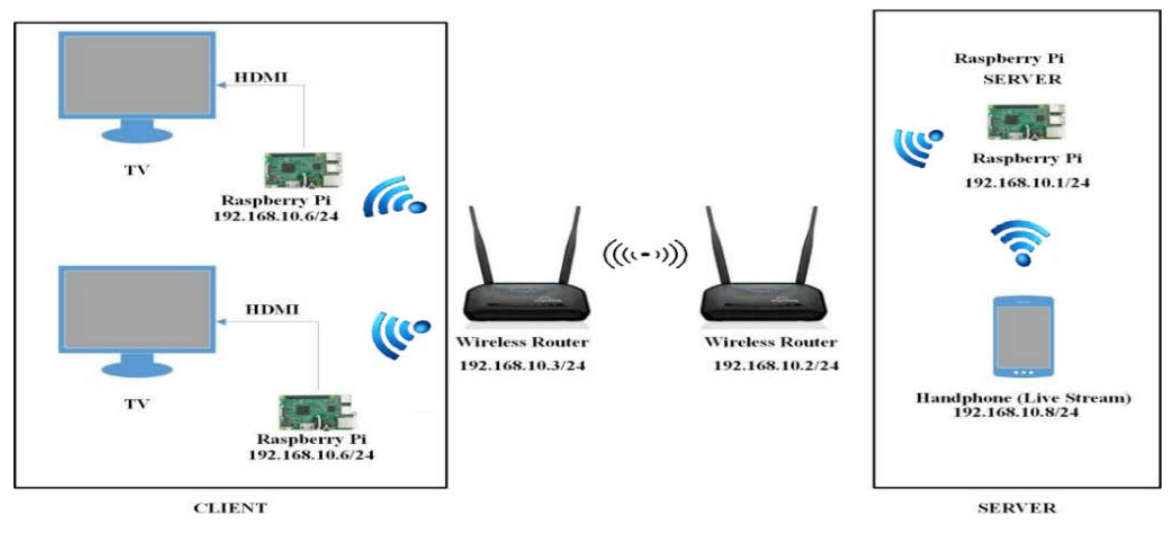

Gambar 1. Topologi Jaringan WDS Yang Digunakan

Desain jaringan memerlukan dua buah access point yang mendukung teknologi WDS. Server berfungsi untuk mengontrol papan informasi digital. Seperti pada gambar 1, penelitian ini dibatasi hanya menggunakan dua unit Raspberry pi sebagai Interface dan penerima data dari server dan satu raspberry pi untuk server, dan dua unit LED TV sebagai perangkat untuk menampilkan informasi yang disambungkan ke Raspberry pi. Untuk skenario penempatan dibagi menjadi dua kondisi. Skenario pertama adalah kondisi NLOS. Seperti pada gambar 2 antara server, router 1 dan router 2 serta raspberry pi tidak berada pada kondisi pandang langsung namun dibatasi halangan berupa tembok dan kaca. Skenario kedua adalah kondisi LOS seperti terlihat pada gambar 3. Pada skenario ini server, router 1, router 2 dan raspberry pi berada pada kondisi pandang langsung. 


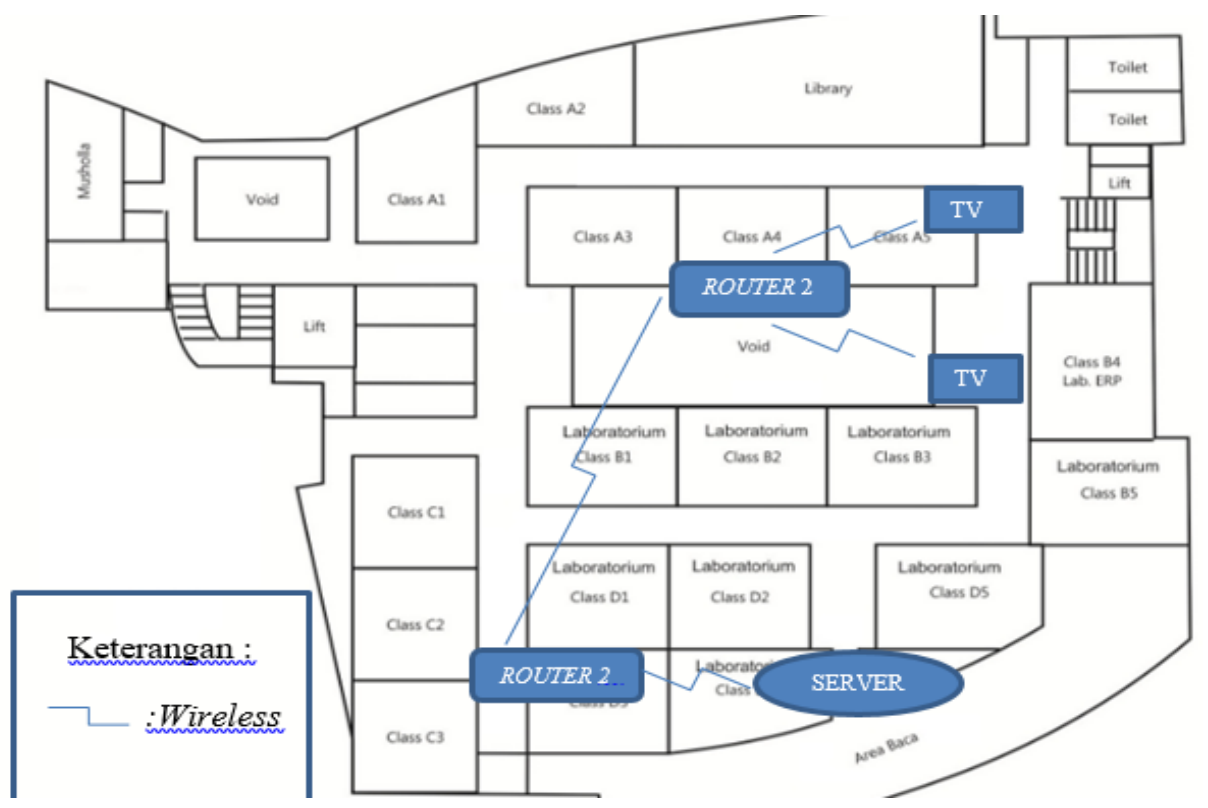

Gambar 2. Skenario 1 Penempatan Perangkat Dengan Kondisi NLOS

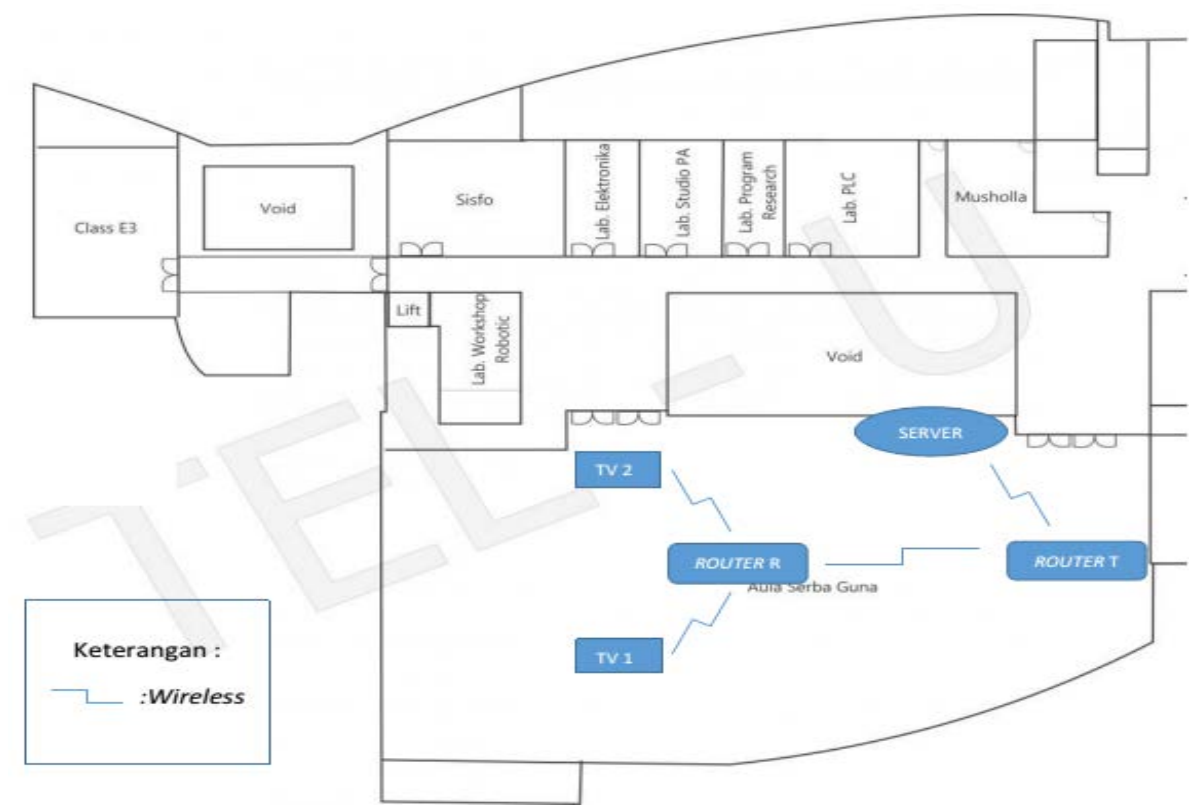

Gambar 3. Skenario 2 Penempatan Perangkat Dengan Kondisi LOS

Pada Skenario 1 dan 2 diatur dengan jarak yang sama yaitu sebagai berikut:
a) Jarak antara server ke router 1
$=15$ meter
b) Jarak antara router 1 ke router 2
$=25$ meter
c) Jarak antara router 2 ke TV 1
$=15$ meter
d) Jarak antara router 2 ke TV 2
$=15$ meter

Dari gambar 2 dan 3 untuk kondisi NLOS maupun LOS didapatkan data bahwa jarak dari Raspberry pi server ke Raspberry pi client yang terhubung ke LED TV adalah: $15 \mathrm{~m}+25 \mathrm{~m}+15 \mathrm{~m}+15=70$ meter

\subsection{Merancang Web Interface}

Proses perancangan tampilan web yang di tampilkan di desain dengan menggunakan bahasa HTML dan CSS. Sebelum melakukan perancangan desain tampilan web server, hal yang harus dilakukan adalah melakukan desain awal untuk penempatan konten yang akan di tampilkan. Pada gambar 4 tampak konten yang akan di muat pada web antara lain yaitu jadwal perkuliahan, logo Universitas, Logo program studi, 
berita-berita terkini, dan video yang akan diputar secara berulang atau menampilkan video dengan layanan live streaming.

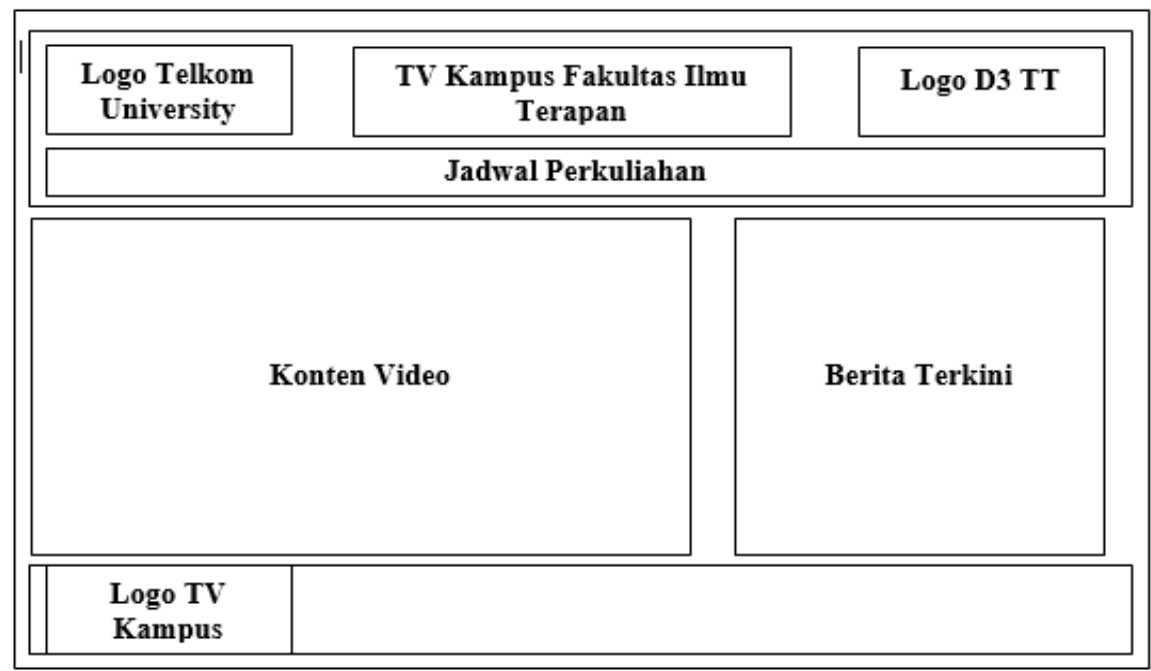

Gambar 4. Rancangan Tampilan Web Di Sisi Client

\subsection{Konfigurasi Raspberry PI Server}

a) Instalasi web server Apache2 .

Seperti yang telah diketahui Apache adalah salah satu web server open source yang digunakan untuk menjalankan web server. Cara instalasinya yaitu dengan memasukkan perintah seperti di bawah ini pada terminal di raspberry pi.

"sudo apt-get update"

Command diatas berfungsi untuk memperbarui semua versi sistem pada raspberry pi yang lama menjadi versi terbaru yang kemudian dilanjutkan dengan instalasi web server dengan menggunakan perintah berikut.

"sudo apt-get install apache2 -y"

b) Untuk menguji apakah web server telah terinstalasi dengan baik maka dilakukan pengecekan pada web browser terlebih dahulu dengan membuka halaman 'http://localhost' atau 'http://(ip raspberry pi)'.

c) Setelah web server berhasil berjalan dengan baik, maka dilanjutkan dengan mengubah web default pada web server, halaman web default adalah halaman html pada folder sistem yang berfungsi menjadi induk folder ketika pemanggilan web server. Cara mengubahnya yaitu dengan membuka terminal pada raspberry pi kemudian masukkan perintah dibawah ini.

"cd /var/www/html"

Perintah ini berfungsi untuk masuk kedalam folder HTML dimana didalam folder tersebut terdapat sebuah file bernama index.html yang kemudian harus diubah menjadi web default dengan perintah di bawah ini.

"sudo chown pi: index.html"

d) Kemudian dilanjutkan dengan instalasi bahasa web php5 agar server dapat memproses file php.

"sudo apt-get install php5 libapache2-mod-php5 -y"

e) Karena web server sudah terinstalasi dengan baik, maka raspberry pi sudah bisa digunakan sebagai server dan bisa meletakkan web yang telah didesain sebagai tampilan untuk papan informasi digital kedalam folder 'var/www/html'. 


\section{HASIL DAN PEMBAHASAN}

Setelah melakukan 4 langkah yang direncanakan yaitu merancang topologi jaringan WDS, merancang web interface, melakukan konfigurasi server dan menanamkan web interface ke raspberry pi kemudian kami juga melakukan pengujian fungsionalitas dan pengukuran QOS, berdasarkan parameter throughput, delay dan jitter. Adapun hasil yang kami dapatkan adalah sebagai berikut:

\subsection{Acuan Analisis}

Standar yang digunakan untuk melihat performansi mengacu pada standar ITU-T dan Tiphon[10][11] yaitu:

a) Delay untuk layanan real-time video adalah dibawah $150 \mathrm{~ms}$

b) Delay untuk layanan real-time Voip adalah dibawah $100 \mathrm{~ms}$

c) Standar jitter untuk layanan video adalah dibawah $30 \mathrm{~ms}$

Kualitas video streaming dan live streaming yang dihasilkan dapat mengetahui QOS dengan analisis jaringan yang menggunakan perangkat lunak Wireshark[12]. Pada pengujian yang dilakukan mengambil sampel paket yang terbaca pada Wireshark. Pengujian pertama scanning dilakukan terhadap layanan video streaming menggunakan skenario posisi LOS antara server dengan LED TV dan posisi NLOS, kemudian pengujian kedua scanning dilakukan terhadap layanan live streaming yang juga dilakukan menggunakan posisi NLOS dan LOS.

\subsection{Analisis Throughput}

Berdasarkan hasil yang didapatkan, tampak pada gambar 5 bahwa nilai throughput tertinggi pada video streaming saat kondisi LOS dibandingkan kondisi NLOS, begitu juga untuk layanan live streaming kondisi LOS lebih baik dibandingkan kondisi NLOS.

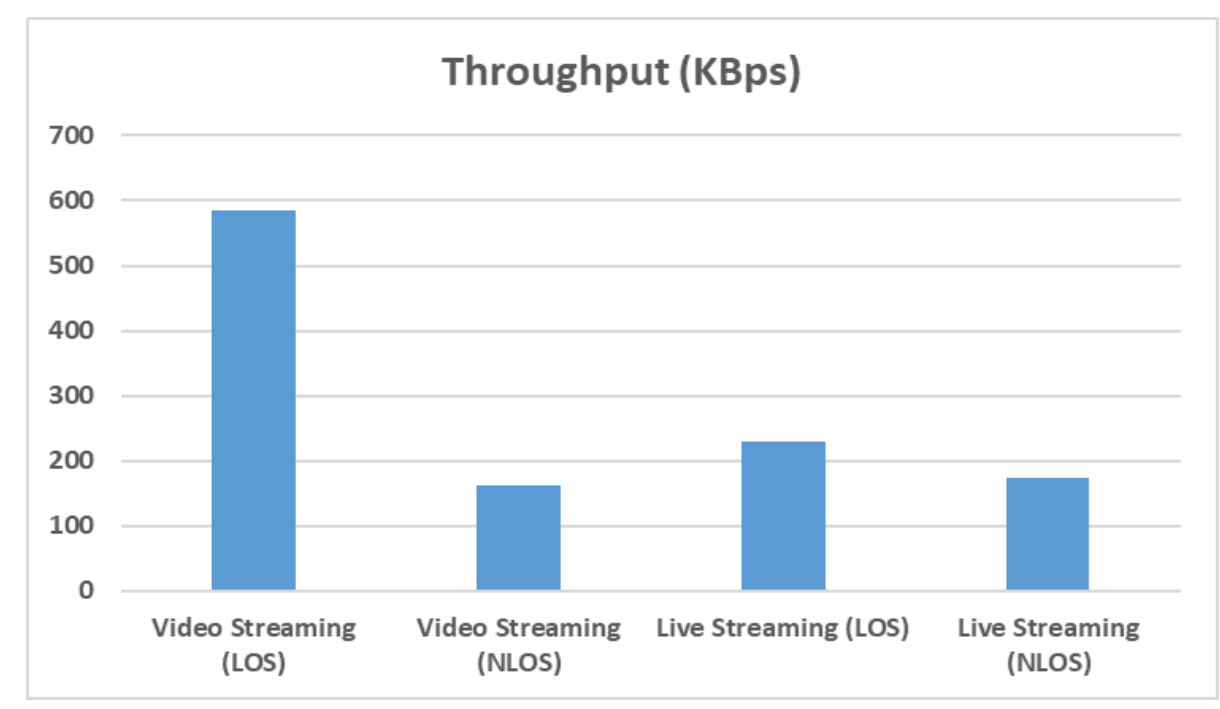

Gambar 5. Nilai Throughput

Secara detail pada tabel 1 terlihat bahwa nilai throughput yang didapatkan masih sesuai dengan standar minimum yang ditetapkan oleh ITU-T dan Tiphon. Dari hasil ini masih memungkinkan menerapkan skenario NLOS karena hasil masih dalam kondisi yang baik, namun untuk hasil yang lebih baik kami merekomendasikan untuk menempatkan server, router 1,router 2 dan Raspberry pi dengan kondisi LOS.

Tabel 1. Hasil pengujian throughput

\begin{tabular}{lc}
\hline \multicolumn{1}{c}{ Layanan } & Throughput (KBps) \\
\hline Video Streaming (LOS) & 585 \\
Video Streaming & \\
(NLOS) & 162 \\
Live Streaming (LOS) & 230 \\
Live Streaming (NLOS) & 173 \\
\hline
\end{tabular}


Hasil pengukuran nilai throughput yang baik terlihat juga dari sisi tampilan papan pengumuman. Pada gambar 6 terlihat video live streaming berjalan dengan lancar ketika ditampilkan pada papan pengumuman. Video bersumber dari handphone yang mengirimkan video secara live streaming melalui jaringan wds.

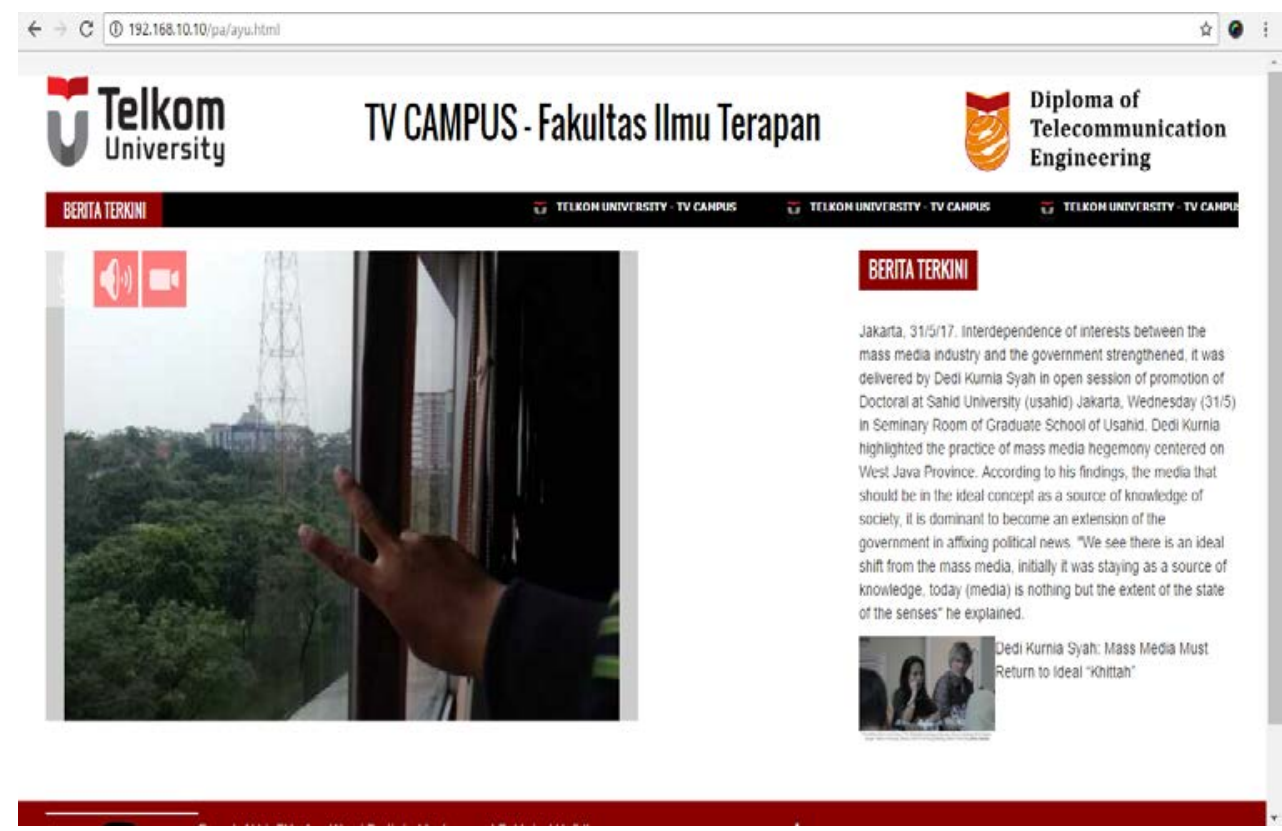

Gambar 6. Tampilan Papan Informasi Digital

\subsection{Analisis Delay}

Semakin besar jumlah link yang harus dilalui paket untuk mencapai destination maka waktu yang dibutuhkan untuk mencapai destination akan semakin besar pula. Pada gambar 7 menunjukkan bahwa untuk layanan video streaming dan live streaming, kondisi LOS memberikan nilai delay yang lebih baik daripada kondisi NLOS. Pada Tabel 2 dapat dilihat hasil pengukuran nilai delay data yang ditransmisikan. Dari hasil pengukuran delay untuk kondisi LOS dan NLOS masuk dalam kategori sangat bagus menurut standar ETSI dan ITU-T karena delay $<150 \mathrm{~ms}$.

Tabel 2. Hasil Pengujian Delay

\begin{tabular}{lcc}
\hline \multicolumn{1}{c}{ Layanan } & $\begin{array}{c}\text { Delay } \\
(\mathbf{m s})\end{array}$ & $\begin{array}{c}\text { Kategori } \\
\text { Tiphon }\end{array}$ \\
\hline Video Streaming (LOS) & 1.7 & $\begin{array}{c}\text { Sangat Bagus } \\
\text { Sangat Bagus }\end{array}$ \\
Video Streaming & 5.9 & \\
(NLOS) & 3.3 & Sangat Bagus \\
Live Streaming (LOS) & 4.2 & Sangat Bagus \\
Live Streaming (NLOS) &
\end{tabular}




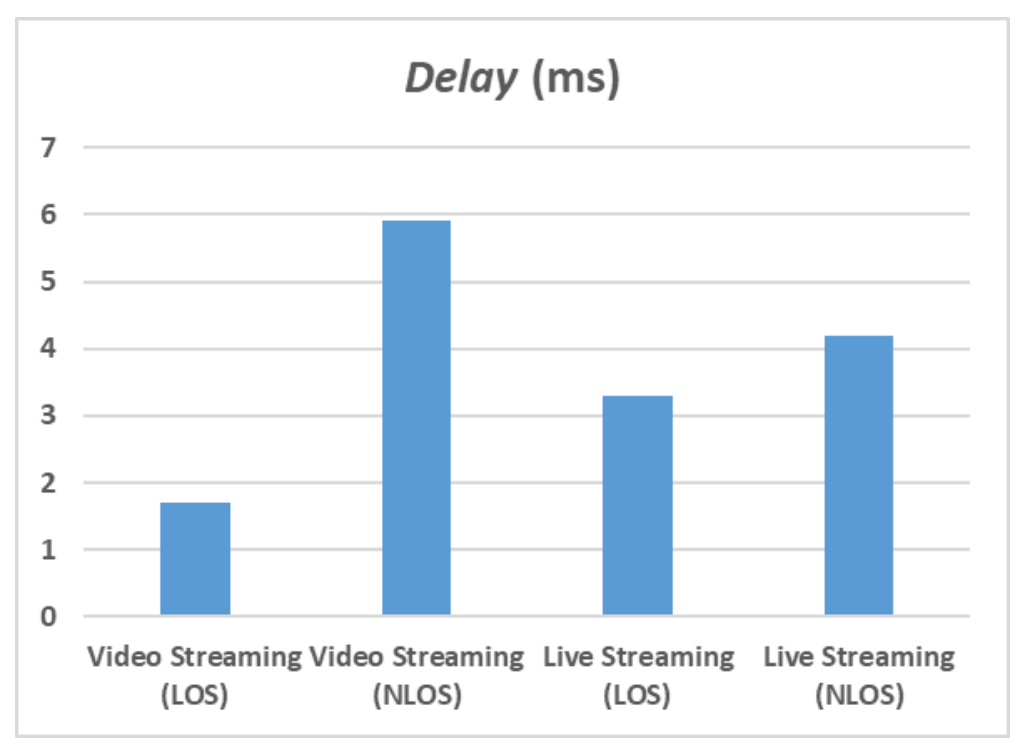

Gambar 7. Nilai Delay

\subsection{Analisis Jitter}

Dari hasil pengamatan yang ditampilkan pada tabel 3 didapatkan nilai Jitter yang tinggi untuk layanan NLOS namun masih dalam ambang yang baik karena 0 - 75 ms masih kategori baik. Posisi NLOS berpengaruh terhadap jitter karena menyebabkan variasi delay, namun karena jarak percobaan berada di dalam gedung yang sama dan jarak kurang dari 100 meter sehingga hasil jitter masih baik. Pada gambar 8 menunjukkan bahwa jitter pada kondisi LOS lebih baik jika dibandingkan dengan NLOS untuk layanan video streaming maupun live streaming.

Tabel 3. Hasil pengujian jitter

\begin{tabular}{lcc}
\hline \multicolumn{1}{c}{ Layanan } & $\begin{array}{c}\text { Jitter } \\
(\mathbf{m s})\end{array}$ & $\begin{array}{c}\text { Kategori } \\
\text { Std }\end{array}$ \\
\hline Video Streaming (LOS) & 2.5 & $\begin{array}{l}\text { Bagus } \\
\text { Video Streaming }\end{array}$ \\
(NLOS) & 8.9 & Bagus \\
Live Streaming (LOS) & 6.19 & Bagus \\
Live Streaming (NLOS) & 7.5 & Bagus \\
\hline
\end{tabular}

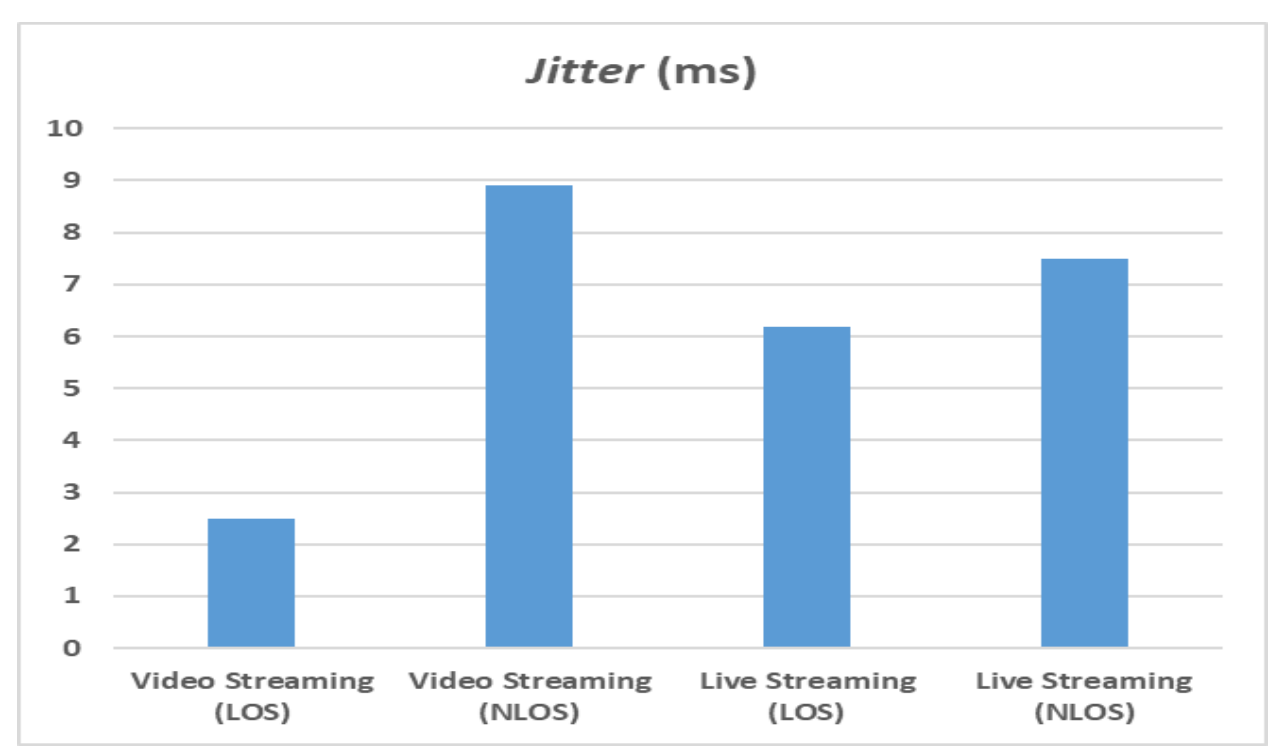

Gambar 8. Nilai Jitter 


\subsection{Analisis Mean Opinion Score (MOS)}

Menurut ITU-T, kualitas audio dan video bersifat subyektif . Ini berarti bahwa dasar pengukuran untuk kualitas audio dan video adalah pendapat pengguna. Namun, pendapat seseorang tentang apa yang baik, mungkin sangat berbeda dengan pendapat orang lain - tidak ada orang yang benar, tidak ada orang yang salah. Dalam penelitian kali ini, kami juga melakukan pengukuran berdasarkan opini publik. Subjek diminta memberikan pendapat mereka dengan menggunakan "skala penilaian". Tujuan dari skala ini adalah untuk menerjemahkan penilaian kualitas subjek menjadi nilai numerik yang dapat dirata-ratakan di seluruh subyek dan faktor eksperimental lainnya. Ada 6 jenis pertanyaan seperti yang tampak pada tabel 4. Pertanyaan yang diajukan meliputi kualitas audio dan video yang dirasakan oleh pengguna.

Tabel 4. Nilai pengukuran MOS

\begin{tabular}{clcc}
\hline No & \multicolumn{1}{c}{ Komponen Penilaian } & $\begin{array}{c}\text { Vilai pengujian } \\
\text { rata-rata }\end{array}$ & $\begin{array}{c}\text { Kategori } \\
\text { Std }\end{array}$ \\
\hline 1 & Tampilan keseluruhan papan informasi & 4.26 & Bagus \\
2 & Kualitas Video Streaming & 4.00 & Bagus \\
3 & Kualitas Live Streaming & 3.93 & Cukup \\
4 & Kualitas Suara video streaming & 4.06 & Bagus \\
5 & Kualitas Suara live streaming & 3.93 & Cukup \\
6 & delay video yang dirasakan & 4.00 & Baik \\
\hline
\end{tabular}

Pada gambar 9 terlihat bahwa dari 30 responden didapatkan hasil pengukuran MOS berada pada range 3.93 sampai 4.26. Nilai tertinggi didapatkan untuk kualitas tampilan papan informasi. Pada MOS menggunakan skala yang paling sering digunakan yaitu skala rating kategori absolut 5-point (ACR): 5 (Sangat Bagus), 4 (Bagus), 3 (Cukup), 2 (Buruk) dan 1 (Sangat Buruk). Hasil yang didapatkan dari subyek dengan nilai rata-rata sebesar 4.

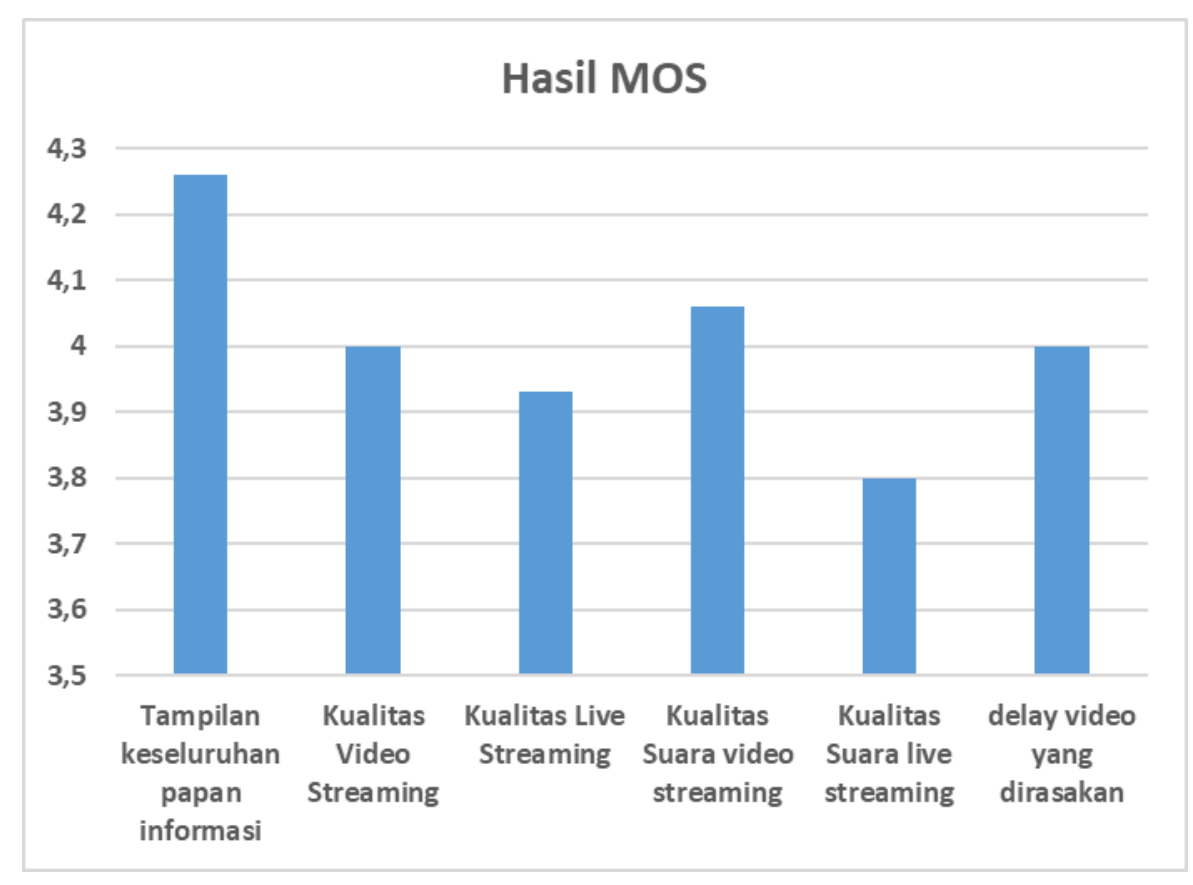

Gambar 9. Nilai MOS

\section{KESIMPULAN}

Setelah diimplementasikannya pada Gedung Selaru Menggunakan Jaringan WDS, maka didapatkan kesimpulan berupa :

a) Pengujian papan informasi digital menggunakan jaringan wireless dengan WDS dilakukan dengan dua skenario dimana skenario pertama yang dilakukan di Gedung Selaru lantai dua 
dengan keadaan NLOS (Non Line of Sight), dan skenario kedua dilakukan di Aula Gedung Selaru lantai empat dengan keadaan LOS (line of Sight).

b) Berdasarkan hasil analisa menggunakan Wireshark, implementasi skenario NLOS yang berada di lantai dua Gedung Selaru yang paling direkomendasikan untuk implementasi yaitu pengujian pertama dengan delay sebesar 5,9 ms untuk video streaming dan 4,2 ms untuk live streaming serta jitter sebesar 8,9 ms untuk video streaming dan 7,5 ms untuk live streaming, throughput diketahui sebesar 162 KBps untuk video streaming \& 173 KBps untuk live streaming.

c) Pada hasil analisa menggunakan Wireshark implementasi skenario LOS di Aula Gedung Selaru Lantai empat yang paling direkomendasikan untuk implementasi yaitu pengujian pertama dengan delay sebesar 1,7 ms untuk video streaming dan 3,3 untuk live streaming serta jitter sebesar 2,5 ms untuk video streaming dan 6,19 ms untuk live streaming, throughput diketahui sebesar $585 \mathrm{kBps}$ untuk video streaming \& $230 \mathrm{kBps}$ untuk live streaming.

d) Setelah melakukan pengujian kelayakan menggunakan skenario LOS dan NLOS dengan kuesioner kepada 30 responden, didapat nilai terendah 3,93 pada komponen kualitas video dan suara live streaming dan nilai rata-rata MOS sebesar 4, artinya masuk dalam kategori baik

\section{DAFTAR PUSTAKA}

[1] Avhad, Jyoti, S. Bhavar, Vedika, S. Chavhan, Sneha, K. Dhole, Tushar, R. and Kapadnis, Jagdish, Y. 2016. "Real Time Digital Notice Board on Cloud Platform". Imperial Journal of Interdisciplinary Research (IJIR), Vol-2, Issue-4, ISSN: 2454-1362.

[2] Darlis, Denny. Tulloh, Rohmat. Saleh, Sheptian K. 2017. "Sistem Media Center Periklanan Pameran di Bandung Berbasis Raspberry pi Menggunakan Serviio”. Jurnal Elektro dan Telekomunikasi Terapan.

[3] Siddharthraju. K, Dhivya Devi. R. December 2016, "Raspberry PI based Wireless Interactive Display”, Volume 4 Issue XII, International Journal for Research in Applied Science \& Engineering Technology (IJRASET), ISSN: 2321-9653.

[4] Rizal Panuntun, Adian Fatchur Rochim, Kurniawan Teguh Martono, April 2015. "Perancangan Papan Informasi Digital Berbasis Web pada Raspberry pi”, Jurnal Teknologi dan Sistem Komputer, Vol.3, No.2, (e-ISSN: 2338-0403).

[5] Vinod B. Jadhav, Tejas S. Nagwanshi, Yogesh P. Patil, Deepak R. Patil, May 2016. "Digital Notice Board Using Raspberry PI”, International Research Journal of Engineering and Technology (IRJET), Volume: 03 Issue: 05 | May-2016, e-ISSN: 2395 -0056, p-ISSN: 2395-0072.

[6] J-P. Jeong, W-S. Lim, and Y-J. Suh, 2013. “Throughput Enhancement for WDS-based WLANs”, in 22nd International Conference on Computer Communications and Networks (ICCCN)

[7] Wibisono, Gumilar, 2014 "Implentasi Dan Analisis Pebandingan Perfomansi Jaringan WDS (Wireless Distribution System) Mode Bridge Dan Mode Repeater”, Telkom University; Bandung

[8] B. Zubairu, "Designing of Wireless Distribution System Network (WDSN) Model”, in Academic Journal of Interdisciplinary Studies, MCSER Publishing, Rome-Italy, Vol 2 No 7, September 2013.

[9] M. Richardson and S. Wallace. 2012. Getting Started with Raspberry pi. United States of America: Maker Media, Inc.

[10] Keunggulan Raspberry pi 3, https://www.raspberrypi.org/help/faqs/\#introWhatIs (online) diakses pada 15 Juni 2017

[11] ETSI, “Telecommunications and Internet Protocol Harmonization Over Networks (TIPHON), 2006; General aspects of Quality of Service (QoS)”, Technical Report.

[12] ITU-T G.1010, 2011 "SERIES G: Transmission Systems And Media, Digital Systems and Network: Quality of Service and Performance”, End-user multimedia QoS Categories. 